\title{
Withdrawal from labour force due to work disability in patients with ankylosing spondylitis
}

Department of Internal Medicine, Division of Rheumatology, University Hospital Maastricht, The

Netherlands

A Boonen

$\mathrm{S}$ van der Linden

Division of Public Health, TNO

Prevention and Health, Leiden, The Netherlands A Chorus

Netherlands Expert Centre for Work-related

Musculoskeletal

Disorders, University Hospital Dijkzigt and

Erasmus University

Rotterdam, The

Netherlands

H Miedema

Department of Internal Medicine, Division of Rheumatology, University Hospital Maastricht, The

Netherlands and Limburg University Centre, Diepenbeek, Belgium

D van der Heijde

Department of Internal Medicine, Division of

Rheumatology, University Hospital Maastricht and Atrium Medical Centre, Heerlen, The Netherlands R Landewé

Department of Methodology and Statistics, University of Maastricht, The Netherlands

H Schouten

Maasland Ziekenhuis, Sittard, The

Netherlands

$\mathrm{H}$ van der Tempel

Correspondence to: Dr A Boonen, Department of Internal Medicine, Division of Rheumatology, University Hospital Maastricht, P O Box 5800 , 6202 AZ Maastricht, The Netherlands

aboo@sint.azm.nl

A Boonen, A Chorus, H Miedema, D van der Heijde, R Landewé, H Schouten, $H$ van der Tempel, $S$ van der Linden

\begin{abstract}
Objective-To investigate withdrawal from the labour force because of inability to work owing to ankylosing spondylitis (AS) and to determine the characteristics of patients with no job because of work disability attributable to AS.

Methods-A postal questionnaire was sent to 709 patients with AS aged 16-60 years followed up by a rheumatologist. KaplanMeier survival statistics were used to assess the time lapse between diagnosis and withdrawal from work. Standardised incidence ratios were calculated to compare withdrawal from the labour force in patients with AS and the general population. Determinants of withdrawal were assessed by Cox's proportional hazard regression analysis using variables assumed to be time independent. Cross sectional characteristics of patients without a job owing to disability were further analysed by simple and multiple regression analyses.
\end{abstract}

Results-A total of 658 patients returned the questionnaire. Of 529 patients with a paid job before diagnosis of AS, $5 \%$ had left the labour force within the first year after the diagnosis, $13 \%$ after 5 years, $21 \%$ after 10 years, $23 \%$ after 15 years, and $31 \%$ after 20 years. Age and sex adjusted risk for withdrawal was $3.1(95 \%$ CI 2.5 to 3.7$)$ times higher than in the general population. In patients with AS, determinants of withdrawal from work were older age at diagnosis, manual work, and coping strategies characterised by limiting or adapting activities. Patients with work disability at the time of the study were older, came from a lower social class, and were more likely to have total hip replacement, peripheral arthritis, or comorbidity. Moreover, they reported worse physical function (BAS-FI), experienced lower quality of life, and more often had extraspinal disease than those with a job.

Conclusion-Withdrawal from work is 3.1 times higher in patients with AS than expected in the general population. Within patients, higher age at diagnosis, manual work, and unfavourable coping strategies are important determinants of withdrawal. Patients without a job experience a lower quality of life.

(Ann Rheum Dis 2001;60:1033-1039)

Ankylosing spondylitis (AS) is a chronic rheumatic disorder with an estimated prevalence of $0.08-0.86 \%$. $^{1}$ The disease usually starts in the third decade of life and affects men three times as often as women. ${ }^{2}$ Spinal and extraspinal manifestations may contribute to functional limitations. ${ }^{3}$ Work disability is an important socioeconomic outcome since it is associated with psychosocial ${ }^{4}$ and financial ${ }^{5}$ consequences for patients as well as for society. In a recent cross sectional study we found that age and sex adjusted employment in AS was $11 \%$ lower ( $15 \%$ in men, $5 \%$ in women) and official work disability was $15 \%$ higher (in both sexes) than in the general Dutch population. ${ }^{6}$ We have undertaken a study of withdrawal from the labour force as a result of AS in patients who had a job before the diagnosis was established. In addition, factors associated with withdrawal and characteristics of patients with work disability attributable to AS were analysed.

\section{Methods}

PATIENTS

Patients were selected from the nationwide Dutch Standard Diagnosis Register of Rheumatic Diseases (SDR) in which 37 rheumatology practices $(66 \%)$ and $80 \%$ of all Dutch rheumatologists participated at the time of the study. ${ }^{7}$ Thirteen regional and two academic practices, geographically spread throughout the country, were invited and agreed to participate. Selected patients had to have a definite diagnosis of AS and to be aged 16-60 years. The estimated total number of patients with AS in the Netherlands is $11700,{ }^{8}$ of whom probably $40-50 \%$ are followed up by a rheumatologist, when taking into account the proportion of rheumatologists participating in the SDR and the number of patients with AS in this register.

\section{QUESTIONNAIRE}

In September 1997 patients received a postal questionnaire on sociodemographic, disease related, and work related variables. Sociodemographic factors comprised sex, age, race, marital status, family situation, education, profession, income, work status, and conditions at the workplace. Educational level was dichotomised into $>12$ years and $\leqslant 12$ years of formal education. For classification of professions, the Statistics Netherlands Job Classification System was applied. ${ }^{9}$ Professions were recoded into manual work (jobs in agricultural, industrial, and transport sectors) and non-manual work (jobs in administrative, servicing, and specialist or managerial sectors). Disease related questions assessed age at diagnosis, comorbidity, medication, extraspinal manifestations of AS (inflammatory bowel disease (IBD) and peripheral arthritis), presence of 
Table 1 Age and sex adjusted risk ratios (95\% CI) for withdrawal from labour force in ankylosing spondylitis (AS) compared with the general Dutch population

\begin{tabular}{|c|c|c|c|c|c|c|c|c|c|}
\hline & \multicolumn{3}{|c|}{ Male AS patients } & \multicolumn{3}{|c|}{ Female AS patients } & \multicolumn{3}{|c|}{ All AS patients } \\
\hline & Observed & Expected & $R R(95 \% C I)$ & Observed & Expected & $R R(95 \% C I)$ & Observed & Expected & $R R(95 \% C I)$ \\
\hline$<25$ years & 3 & 0.36 & $8.3(1.7$ to 24.3$)$ & 1 & 0.24 & $4.2(0.1$ to 23.3$)$ & 4 & 0.59 & $6.7(1.8$ to 17.1$)$ \\
\hline 25-34 years & 31 & 5.28 & $5.9(4.0$ to 8.3$)$ & 9 & 4.66 & $1.9(0.9$ to 3.7$)$ & 40 & 9.94 & $4.0(2.9$ to 5.5$)$ \\
\hline $35-44$ years & 27 & 7.52 & $3.6(2.4$ to 5.2$)$ & 12 & 5.53 & $2.2(1.1$ to 3.8$)$ & 39 & 13.05 & $3.0(2.1$ to 4.1$)$ \\
\hline $45-54$ years & 23 & 8.19 & $2.8(1.8$ to 4.2$)$ & 6 & 2.58 & $2.3(0.4$ to 5.1$)$ & 29 & 10.77 & $2.7(1.8$ to 3.9$)$ \\
\hline$\geqslant 55$ years & 2 & 2.03 & $0.98(0.1$ to 3.6$)$ & 0 & 0.30 & - & 2 & 2.33 & $0.85(0.1$ to 3.1$)$ \\
\hline All patients & 86 & 23.38 & $3.7(2.9$ to 4.4$)$ & 28 & 13.32 & $2.1(1.4$ to 3.0$)$ & 114 & 36.69 & $3.1(2.5$ to 3.7$)$ \\
\hline
\end{tabular}

$\mathrm{RR}=$ standardised risk ratios.

Table 2 Variables associated with withdrawal from labour force because of ankylosing spondylitis (AS) related work disability, assessed by Cox's proportional hazard regression analysis

\begin{tabular}{llc}
\hline & HR (95\% CI) & p Value \\
\hline Age at diagnosis (cut off $\geqslant 35$ years) & $1.98(1.30$ to 3.03$)$ & 0.002 \\
Manual profession & $2.27(1.52$ to 3.38$)$ & 0.0001 \\
Coping with pain by limiting activities & $2.32(1.48$ to 3.64$)$ & 0.0002 \\
Coping with limitations by adapting activities & $6.99(3.13$ to 15.63$)$ & $<0.000$ \\
\hline
\end{tabular}

$\mathrm{HR}=$ hazard ratio disability. In cases where the disability exceeds $15 \%$, a benefit is allowed incrementally ranging from $25 \%$ to $70 \%$ of the former gross wage. Benefits are financed through social contributions from employees and employers. Patients with partial work disability can continue in part time jobs. In 1993 disability criteria changed in the Netherlands to reduce the work disability rates. Before 1993 work disability payments were allowed if a person could not perform his or her profession because of medical restrictions, taking into account age and unemployment figures in the region where the person was living. Since 1993 work disability payments are allowed if there are objective medical restrictions to earn the wage of one's present job, independent of age. In addition, the method to calculate the disability benefit changed and the period of attributed disability was restricted to a maximum of 5 years.

STATISTICS

Kaplan-Meier analysis was applied to patients with a paid job before diagnosis of AS. Leaving the labour force completely because of AS related work disability was considered an event. Patients who received partial work disability benefit but continued to work were not considered to have an event and patients who had left the labour force for reasons other than AS were censored. The risk for withdrawal from the labour force in patients with AS was compared with that of the general population by calculating standardised risk ratios (SRR) for five age categories in men and women separately, using incidence rates of complete work disability benefits in the general Dutch population in 1998 (Dutch Central Bureau of Statistics, unpublished data). Determinants of withdrawal from the labour force were assessed using Cox's proportional hazard regression analysis with backward elimination according to the likelihood ratio test (probability for removal $=0.1$, with age at diagnosis of disease (dichotomised at $\geqslant 35$ years), sex, educational level, profession, and the eight coping strategies as covariates. To assess the influence of the change in work disability criteria in 1993, a time dependent Cox regression was performed with number of years working while suffering from AS before or after 1993 as the time dependent covariate. Possible interactions between the four variables of the final model were assessed in a new Cox's proportional hazard regression, forcing the main effects into the model and selecting all possible interactions by backward elimination. Finally, using the Cox regression equation, three subgroups of
$100 \%$ is regarded as full, while the other categories are considered as partial work 

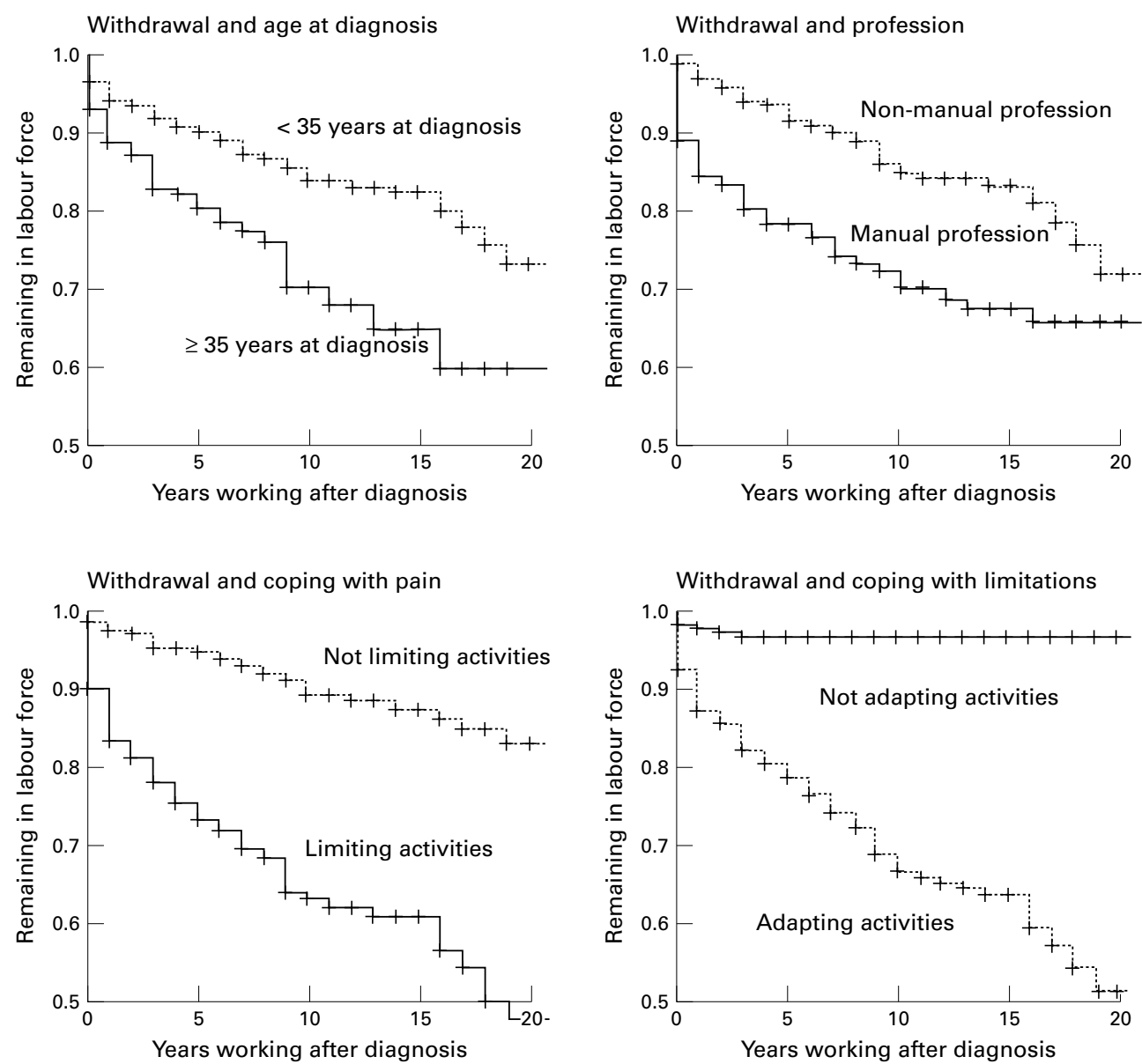

Figure 1 Kaplan-Meier curves illustrating probability to remain in the labour force for each of the risk factors in the Cox regression analysis.

patients with different risks for withdrawal from the labour force were formed and Kaplan-Meier survival statistics were computed for each group.

To assess the characteristics of those with work disability at the time of the survey, we first compared the characteristics of patients in each of the following three groups: (1) those having a job without disability, (2) those having a (part time) job and (partial) work disability, and (3) those having work disability but no job. We then compared those having a job without disability with those having work disability and no paid job. The differences between the groups

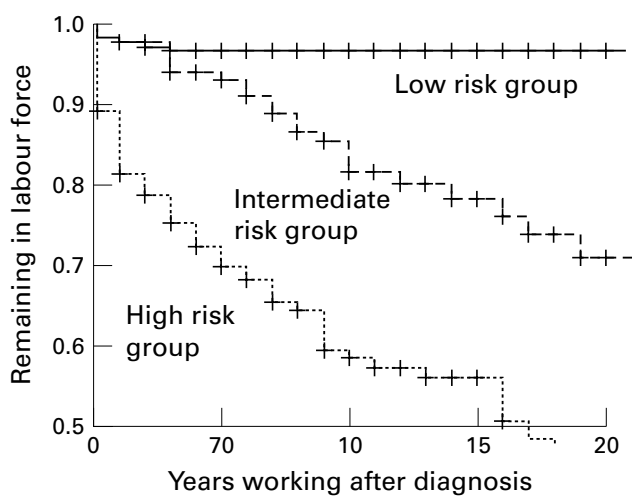

Figure 2 Kaplan-Meier curves illustrating withdrawal from the labour force for three different risk groups of patients with $A S$. were analysed univariately by the $t$ test, $\chi^{2}$ test, and by multiple logistic regression with backward elimination according to the likelihood ratio test. Interactions between the variables of the final regression model were sought. Finally, the contribution of work disability to variations in BAS-FI, BAS-DAI, BAS-G, RAND-36, GHQ, and MFI was analysed in multiple linear regressions while controlling for demographic (age, sex, and social class) and disease characteristics (disease duration, extraspinal disease, and comorbidity). Statistical tests were performed using SPSS 9.0.

\section{Results}

RESPONSE

A total of 1092 patients with AS from the 15 rheumatology practices were sampled. The current postal address of 152 patients could not be retrieved. Of the 940 remaining patients, 709 agreed to participate and received the questionnaire which was completed by 658 patients. This accounts for a response rate of $70.0 \%$. Non-participants did not differ in age and sex from participants. The results of labour force participation and work disability have been described in detail elsewhere. ${ }^{6}$

\section{WITHDRAWAL FROM LABOUR FORCE}

Five hundred and twenty nine of the 658 patients $(80.4 \%)$ had a paid job before diagnosis of AS. The mean (SD) age at diagnosis was 
Table 3 Characteristics of patients with ankylosing spondylitis (AS) who have a job (without work disability) compared with those with a part time job and partial work disability and those with work disability without a job

\begin{tabular}{|c|c|c|c|}
\hline & $\begin{array}{l}\text { Work, no } \\
\text { disability } \\
(n=338)\end{array}$ & $\begin{array}{l}\text { Work and } \\
\text { disability } \\
(n=83)\end{array}$ & $\begin{array}{l}\text { Work disability, } \\
\text { no job } \\
(n=136)\end{array}$ \\
\hline Male (\%) & 77.2 & 78.3 & 72.1 \\
\hline Mean (SD) age (years) & $41.5(8.9)$ & $45.6(7.3)$ & $48.7(7.7)$ \\
\hline Mean (SD) disease duration (years) & $11.4(7.8)$ & $13.3(8.0)$ & $12.4(8.1)$ \\
\hline Education $\leqslant 12$ years $(\%)$ & 71.0 & 90.4 & 90.4 \\
\hline Manual profession (\%) & 29.1 & 36.1 & 47.8 \\
\hline Living with partner (\%) & 85.2 & 83.1 & 87.5 \\
\hline NSAID use (\%) & 79.7 & 85.5 & 87.9 \\
\hline IBD $(\%)$ & 3.8 & 1.2 & 8.8 \\
\hline Peripheral arthritis (\%) & 16.3 & 27.7 & 34.6 \\
\hline THR (\%) & 2.1 & 2.4 & 8.8 \\
\hline Comorbidity (\%) & 30.8 & 34.9 & 65.4 \\
\hline Mean (SD) BAS-FI (0-10) & $2.4(2.1)$ & $4.7(1.9)$ & $6.0(2.1)$ \\
\hline Mean (SD) BAS-DAI $(0-10)$ & $3.0(2.1)$ & $4.6(2.0)$ & $5.4(2.5)$ \\
\hline Mean (SD) BAS-G $(0-10)$ & $3.2(2.4)$ & $5.3(2.1)$ & $6.0(2.3)$ \\
\hline
\end{tabular}

NSAID = non-steroidal anti-inflammatory drug; IBD = inflammatory bowel disease; $\mathrm{THR}=$ total hip replacement.

Table 4 Multiple logistic regression analysis with sociodemographic (age, sex, education, and profession) and disease related variables (disease duration, inflammatory bowel disease, peripheral arthritis, and total hip replacement) to asssess characteristics of work disabled patients with ankylosing spondylitis $(A S)(n=136)$ compared with patients with AS having a paid job without work disability $(n=338)$ at the time of the survey

\begin{tabular}{lllc}
\hline & OR & $95 \%$ CI & $p$ Value \\
\hline Age & 1.09 & 1.06 to 1.13 & $<0.0000$ \\
$\leqslant 12$ years formal education & 3.17 & 1.55 to 6.48 & 0.001 \\
Manual profession & 1.80 & 1.10 to 2.97 & 0.02 \\
Comorbidity & 3.15 & 1.96 to 5.09 & $<0.000$ \\
Peripheral arthritis & 2.02 & 1.19 to 3.43 & 0.004 \\
Total hip replacement & 6.52 & 2.15 to 19.83 & $<0.000$ \\
\hline
\end{tabular}

$\mathrm{OR}=$ odds ratio.
Netherlands in 1993 had no statistically significant influence on the withdrawal rate as shown by time dependent Cox regression $(\mathrm{p}=0.47)$. Table 2 shows determinants of withdrawal as assessed by Cox's proportional hazard regression analysis. Older age at diagnosis, manual work, and two specific coping strategies but not sex and educational level were associated with withdrawal from the labour force. Figure 1 illustrates the influence of these factors on the Kaplan-Meier survival curves; no interactions were seen.

Three different groups at risk for withdrawal from the labour force could be distinguished according to the Cox regression equation. The first group with high risk for withdrawal $36 \%$ of patients) had both unfavourable coping strategies (limiting activities when faced with pain and reducing activities when faced with limitations). The second group with low risk for withdrawal (38\% of patients) had both favourable coping strategies (not limiting activities when faced with pain and not reducing activities when faced with limitations) and the group with intermediate risk for withdrawal ( $26 \%$ of patients) had one of two unfavourable coping strategies. The Kaplan-Meier survival curves of these three risk groups are shown in fig 2 .

CHARACTERISTICS OF WORK DISABLED PATIENTS At the time of the study, 338 of the 658 patients had a paid job without work disability, 83 patients had a (part-time) job and (partial) work disability, and 136 had work disability but no job. In addition, 27 patients had never had a job and 110 patients had left the labour force but for reasons other than AS related work disability. The sociodemographic and disease characteristics of the three groups with a job and/or work disability are compared in table 3 . Older age, longer disease duration, lower social class (educational level and type of job), presence of comorbidity, extraspinal disease (IBD and peripheral arthritis), and THR were characteristics of patients without a job. In multiple logistic regression analysis, patients with a job but no work disability were compared with those who had left the labour force because of work disability. The result of the multiple logistic regression analysis with age, sex, disease duration, education, profession, comorbidity, THR, and extraspinal disease (IBD and peripheral arthritis) are presented in table 4. Sex, disease duration, and IBD were eliminated as independent discriminators. Having a THR was highly associated with being work disabled. No interactions were found between the variables of the final model. The group without a job because of work disability reported an increased frequency of psychopathology (GHQ-12), worse physical function (BAS-FI), higher disease activity (BAS-DAI), worse perceived health (BAS-G and RAND-36), and higher levels of fatigue (MFI) (table 5). Also, when adjustments were made for differences in demographic characteristics, comorbidity, THR and extraspinal disease, work disability remained significantly associated with each of these outcome variables because of the low number of observations in women. The change in disability criteria in the 
Table 5 Simple regression analyses to compare patients with ankylosing spondylitis (AS) having a job without disability with those with work disability without a job

\begin{tabular}{|c|c|c|c|}
\hline & $\begin{array}{l}\text { Work, no disability } \\
(n=338)\end{array}$ & $\begin{array}{l}\text { Disability, no work } \\
(n=136)\end{array}$ & $p$ Value \\
\hline Adaptations at work place ${ }^{\star}$ & $76 / 338(22 \%)$ & $31 / 136(23 \%)$ & 0.9 \\
\hline BAS-FI $(0-10)$ & $2.4(2.1)$ & $6.0(2.1)$ & $<0.000$ \\
\hline BAS-DAI $(0-10)$ & $3.0(2.1)$ & $5.4(2.5)$ & $<0.000$ \\
\hline BAS-G $(0-10)$ & $3.2(2.4)$ & $6.0(2.3)$ & $<0.000$ \\
\hline \multicolumn{4}{|l|}{ RAND-36 (0-100) } \\
\hline Physical function & $78.3(16.3)$ & $42.1(22.9)$ & $<0.000$ \\
\hline Social function & $85.0(19.4)$ & $57.4(25.9)$ & $<0.000$ \\
\hline Physical role & $73.7(36.2)$ & $29.3(37.8)$ & $<0.000$ \\
\hline Social role & $88.2(27.3)$ & $62.7(43.2)$ & $<0.000$ \\
\hline Mental health & $76.2(17.2)$ & $64.2(20.0)$ & $<0.000$ \\
\hline Reduced vitality & $59.4(18.7)$ & $42.8(18.9)$ & $<0.000$ \\
\hline Pain & $68.4(18.9)$ & $43.6(19.6)$ & $<0.000$ \\
\hline General health & $59.2(20.2)$ & $38.2(20.5)$ & $<0.000$ \\
\hline Health change & $39.3(13.3)$ & $30.2(17.9)$ & $<0.000$ \\
\hline \multicolumn{4}{|l|}{ GHQ } \\
\hline GHQ $\geqslant 3 ; n(\%)$ & $77 / 337(23)$ & $66 / 134(50)$ & $<0.000$ \\
\hline \multicolumn{4}{|l|}{ MFI $(0-20)$} \\
\hline General fatigue & $11.4(3.5)$ & $14.6(3.5)$ & $<0.000$ \\
\hline Physical fatigue & $10.6(3.8)$ & $14.2(3.5)$ & $<0.000$ \\
\hline Reduced activity & $8.5(3.3)$ & $12.7(3.9)$ & $<0.000$ \\
\hline Reduced motivation & $8.5(3.3)$ & $11.2(3.7)$ & $<0.000$ \\
\hline Mental fatigue & $8.1(3.7)$ & $10.2(4.2)$ & $<0.000$ \\
\hline
\end{tabular}

Values are mean (SD)

$\mathrm{GHQ}=$ general health questionnaire; $\mathrm{MFI}=$ multifactorial fatigue index

^In present or last job. influenced our patient population considerably. Thirdly, it can be argued that patients with problems at the workplace are more likely to consult a rheumatologist which might have inflated the observed withdrawal rate. However, in The Netherlands the rheumatologist has only a minor role in decisions on eligibility for work disability, reducing the chance that those patients with difficulties at the workplace more often consult a rheumatologist. Apart from selection bias, the change in disability criteria in the Netherlands in 1993 posed an additional problem in our retrospective study. A time dependent Cox analysis showed that this change had no measurable influence on the withdrawal rate for patients with AS. Furthermore, given the design of this study, variables to assess determinants of withdrawal were selected carefully. Age at diagnosis, sex, education, type of profession, and coping strategies, ${ }^{22}$ although assessed at the time of the survey, are unlikely to have changed after diagnosis of disease and therefore can be used in predictive models. However, information on peripheral arthritis, THR, IBD, comorbidity, disease activity and severity, and quality of life was only available for the time of the survey and could therefore not be used to analyse predictors for work disability in this retrospective study.

The withdrawal rate in our population was slightly lower than in both a Mexican prospective study $(n=103)$ in which a withdrawal rate of $15 \%$ was observed after 5 years in patients with a mean disease duration of 10 years, ${ }^{23}$ and a French longitudinal study $(n=186)$ which reported a cumulative withdrawal of $36 \%$ after 20 years of disease. ${ }^{24}$ A Finnish inception cohort $(n=76)$ showed lower withdrawal rates in the first years of the disease $(5 \%$ after 10 years), but equal withdrawal after longer disease duration ( $30 \%$ after 25 years). ${ }^{25}$ These studies did not explicitly state whether or not they assessed AS attributable withdrawal while we specifically studied withdrawal because of AS. This difference might contribute to our somewhat more favourable results. In addition, the French cohort included only patients admitted to hospital and might have dealt with more severe disease. On the other hand, a very low withdrawal rate owing to AS related work disability of $13.2 \%$ after a median of 21.4 years of disease was reported in a recent US study on 234 patients. ${ }^{19}$ Compared with our patients, the proportion having a job as a professional/ manager was higher. We can only speculate on the contribution of differences in the social security systems.

As in the French and US cohorts, we found that the type of job was associated with withdrawal from work. ${ }^{19}{ }^{24}$ Interestingly, in our study two behavioural coping strategies were strongly associated with leaving the labour force-namely, coping with pain by limiting activities and coping with limitations by adapting activities. Coping strategies and their influence on outcome have not yet been thoroughly investigated in AS. Coping measured by the CORS, an arthritis specific coping scale, is considered a personality trait of individuals ${ }^{22}$ and therefore stable over time. In other rate. Since mortality from AS seems only slightly increased, ${ }^{21}$ it is unlikely this will have 
musculoskeletal diseases it has been shown that coping strategies are associated with the amount of pain experienced, level of physical functioning, disease activity, and quality of life. ${ }^{26}{ }^{27}$ To our knowledge, this is the first time that coping strategies have been found to be associated with withdrawal from the labour force in musculoskeletal disease. It is clear that unfavourable coping strategies, in the same way as manual professions, may be disease independent risk factors for withdrawal. However, no data are currently available from the general population or other diseases to analyse this issue in more depth.

This study demonstrates the importance of analysing withdrawal from the labour force not only in patients with AS but also in comparison with the general population. Higher age was positively associated with withdrawal within the AS group but negatively associated with withdrawal when compared with the general population.

Withdrawal rates in AS seem lower than in rheumatoid arthritis (RA). Studies in patients with RA published within the last 5 years which have investigated withdrawal from the labour force among patients with a paid job have shown that withdrawal rates are higher than $30 \%$ after 10 years of disease while in studies in patients with AS withdrawal rates of $30 \%$ are only seen after 20 years. ${ }^{28-34}$ In a case-control cohort study in the UK the odds ratio to become economically inactive was 32.0 (95\% CI 5.4 to 1303) for patients with RA compared with controls, which is about 10 times higher than in our study. ${ }^{34}$ In RA, as in AS, higher age at onset of disease, lower social class, higher disease activity, and worse physical function were associated with withdrawal from work in several of these studies. ${ }^{29-32} 34$

When patients with a job at the time of the survey were compared with those with work disability, work disabled patients were older, from a lower social class, with comorbidity, peripheral arthritis, and most had THR. Notably, sex, disease duration, and IBD were not independent characteristics. Work disability was significantly associated with worse quality of life (RAND-36), higher levels of fatigue (MFI), and the presence of psychopathology (GHQ), independent of age, sex, disease duration, comorbidity, THR, and peripheral arthritis. Again, the retrospective study design does not allow us to conclude that patients who become work disabled will lose quality of life or are likely to develop a psychopathological condition. Indeed, the reverse could be true. Prospective studies in other chronic diseases suggest that loss of work results in worse perceived health. ${ }^{4}$ Patients still working did not report adaptations in the workplace more often than those who had left employment in their last job.

Several cross sectional studies of AS reported in the literature found that higher age, lower education, and worse physical function are associated with present work disability. ${ }^{35-37}$ One other study also concluded that patients without employment more often report depression. ${ }^{35}$ In contrast to our findings, a Norwegian study of 99 patients showed that female sex, but not peripheral arthritis, THR, or the presence of a psychopathological condition (GHQ), were associated with inability to work. ${ }^{37}$ Comparison of data on work status from different countries is, however, difficult. Demographic and disease characteristics can vary, and changes in the local labour market or differences in the social security systems can pose varying incentives to leave or remain in the labour force.

In conclusion, withdrawal from the labour force in AS is substantial. Coping strategies may contribute to withdrawal. Work disabled patients with AS report a worse quality of life. This aspect should not be neglected in any holistic approach of the patient. We gratefully thank all rheumatologists from the following cen-
tres who participate in the SDR and took part in this study: Sint tres who participate in the SDR and took part in this study: Sint Antoniusziekenhuis Nieuwegein, Rode Kruisziekenhuis Den huag, Bosch Medicentrum Den Bosch, Sint Laurentiusziekenhuis Roermond, Sint Jansgasthuis Weert, Groene Hartziekenhuis
Gouda, Albert Schweitzerziekenhuis Dordrecht, Kennemer Gouda, Albert Schweitzerziekenhuis Dordrecht, Kennemer
Gasthuis locatie Deo Haarlem, Lievensberg Ziekenhuis Bergen op Zoom, Tweesteden Ziekenhuis Tilburg, Rijnstate Ziekenhuis Arnhem, St Maartenskliniek Nijmegen, Medisch Spectrum Twente Enschede.

1 Braun J, Bollow M, Remlinger G, Eggens U, Rudwaleit M, Distler A, et al. Prevalence of spondylarthropathies in HLA-B27 positive and negative blood donors. Arthritis Rheum 1998;41:58-67.

2 van der Linden SM, Valkenburg HA, de Jongh BM, Cats A. The risk of developing ankylosing spondylitis in HLA-B27 positive individuals. A comparison of relatives of spondylitis patients with the general population. Arthritis Rheum tis patients with
$1984 ; 27: 241-9$.

3 Dalyan M, Guner A, Tuncer S, Bilgic A, Arasil T. Disability in ankylosing spondylitis. Disabil Rehabil 1999;21:74-9.

4 Warr P. Work, unemploymemt and mental health. Oxford: Clarendon Press, 1987.

5 Yelin EH, Henke CJ, Epstein WV. Work disability among persons with musculoskeletal conditions. Arthritis Rheum 1986;29:1322-33.

6 Boonen A, Chorus A, Miedema H, van der Heijde D, van der Tempel H, van der Linden S. Employment, work disability and work days lost in patients with ankylosing spondylitis: a cross-sectional study of Dutch patients. Ann Rheum Dis 2001;60:353-8.

7 Miedema HS, Van der Linden SM, Rasker JJ, Valkenburg HA. National database of patients visiting rheumatologists in the Netherlands: the standard diagnosis register of rheumatic diseases. A report and preliminary analysis. Br J matic diseases. A report an

8 Miedema HS. Reuma in Nederland: de cijfers. Het aantal patienten met chronische reumatische aandoeningen in patienten met chronische reumatische aandoeningen in Nederland. Leiden: Tno Preventie en Gezondheid, 1997.
Statistisch Jaarboek 1998. Voorburg/Heerlen: Centraal Bureau voor Statistiek, 1998

10 Calin A, Garrett S, Whitelock H, Kennedy LG, O'Hea J, Mallorie P, et al. A new approach to defining functional ability in ankylosing spondylitis: the development of the Bath Ankylosing Spondylitis Functional Index. J Rheumatol 1994;21:2281-5.

11 Garrett S, Jenkinson T, Kennedy LG, Whitelock H, Gaisford P, Calin A. A new approach to defining disease status in ankylosing spondylitis: the Bath Ankylosing Spondylitis Disease Activity Index. J Rheumatol 1994;21: 2286-91.

12 Jones SD, Steiner A, Garrett SL, Calin A. The Bath Ankylosing Spondylitis Patient Global Score (BAS-G). Br J losing Spondylitis Patient

13 Stucki G, Stucki S, Bruhlmann P, Maus S, Michel BA. Comparison of the validity and reliability of self-reported Comparison of the validity and reliability of self-
articular indices. Br J Rheumatol 1995;34:760-6.

14 van Lankveld W, van't Pad Bosch P, van de Putte L, Naring G, van der Staak C. Disease-specific stressors in rheumatoid arthritis: coping and well-being. Br J Rheumatol 1994; 33:1067-73

5 McHorney CA, Ware JE Jr, Lu JF, Sherbourne CD. The MOS 36-item Short-Form Health Survey (SF-36): III. Tests of data quality, scaling assumptions, and reliability across diverse patient groups. Med Care 1994;32:40-66.

16 Ware JE Jr, Sherbourne CD. The MOS 36-item short-form health survey (SF-36). I. Conceptual framework and item selection. Med Care 1992;30:473-83.

17 Smets EM, Garssen B, Bonke B, De Haes JC. The Multidimensional Fatigue Inventory (MFI) psychometric qualities of an instrument to assess fatigue. J Psychosom Res 1995;39:315-25.

18 Banks MH. Validation of the General Health Questionnaire in a young community sample. Psychol Med 1983;13:34953 . 
19 Ward M, Kuzis S. Risk factors for work disability in patients with ankylosing spondylitis. J Rheumatol 2001;28. with an 21 .

20 Gran JT, Husby G. Ankylosing spondylitis: a comparative study of patients in an epidemiological survey, and those admitted to a department of rheumatology. J Rheumato $1984 ; 11: 788-93$

21 Lehtinen K. Mortality and causes of death in 398 patients admitted to hospital with ankylosing spondylitis. Ann Rheum Dis 1993;52:174-6.

22 Gunther V, Mur E, Kurz M, Meise U. Stable pattern of stress coping in patients with rheumatoid arthritis. Clin Exp Rheumatol 1994;12:35-43.

23 Ramos-Remus C, Prieto-Parra RE, Michel-Diaz J, Gutierrez-Urena S, Suarez-Almazor ME. A five-year cumulative analysis of labor-status and lost working days in patients with ankylosing spondylitis (AS). Arthritis Rheum Suppl 1998:1136.

24 Guillemin F, Briancon S, Pourel J, Gaucher A. Long-term disability and prolonged sick leaves as outcome measurements in ankylosing spondylitis. Possible predictive factors. ments in ankylosing spondylitis. Po
Arthritis Rheum 1990;33:1001-6.

25 Lehtinen K. Working ability of 76 patients with ankylosing spondylitis. Scand J Rheumatol 1981;10:263-5.

26 Evers AW, Kraaimaat FW, Geenen R, Bijlsma JW. Psychosocial predictors of functional change in recently diagnosed rheumatoid arthritis patients. Behav Res Ther 1998;36: 179-93.

27 van Lankveld W, Naring G, van't Pad Bosch P, van de Putte L. Behavioral coping and physical functioning: the effect of adjusting the level of activity on observed dexterity. J Rheumatol 1999;26:1058-64.

28 Albers JM, Kuper HH, van Riel PL, Prevoo ML, van't Hof MA, van Gestel AM, et al. Socio-economic consequences of rheumatoid arthritis in the first years of the disease. Rheumatology 1999;38:423-30.
29 Fex E, Larsson BM, Nived K, Eberhardt K. Effect of rheumatoid arthritis on work status and social and leisure time activities in patients followed 8 years from onset. J Rheumatol 1998;25:44-50.

30 Jantti J, Aho K, Kaarela K, Kautiainen H. Work disability in an inception cohort of patients with seropositive rheumatoid arthritis: a 20 year study. Rheumatology 1999;38: $1138-41$.

31 Mau W, Bornmann M, Weber H, Weidemann HF, Hecker , Raspe HH. Prediction of permanent work disability in a follow-up study of early rheumatoid arthritis: results of a tree structured analysis using RECPAM. Br J Rheumatol 1996;35:652-9.

32 Wolfe F, Hawley DJ. The longterm outcomes of rheumatoid arthritis. Work disability: a prospective 18 year study of 823 patients. J Rheumatol 1998;25:2108-17.

33 van Jaarsveld CHM, Jacobs JWG, Schrijvers AJP, Van Albada Kuipers GA, Hofman DM, Bijlsma JWJ. Effects of rheumatoid arthritis on employment and social participation during the first years of disease in The Netherlands. Br J Rheumatol 1998;37:848-53.

34 Barrett EM, Scott DGI, Wiles NJ, Symmons DPM. The impact of rheumatoid arthritis on employment status in the early years of disease: a UK community-based study. Rheumatology 2000;39:1403-9.

35 Roussou E, Kennedy LG, Garrett S, Calin A. Socioeconomic status in ankylosing spondylitis: relationship between occupation and disease activity. J Rheumatol 1997;24:908-11.

36 Ramos-Remus C, Macias MA, Suarez-Almazor ME, Prieto RE, Gutierrez-Urenam S. Labor status and working-days lost in a consecutive sample of 103 patients with anlylosing spondylitis (AS). Arthritis Rheum Suppl 1997:1392.

37 Gran JT, Skomsvoll JF. The outcome of ankylosing spondylitis: a study of 100 patients. Br J Rheumatol 1997; 36:766-71. 